06

\title{
Высокотвердые наноструктурные керамико-металлические покрытия с низким уровнем макронапряжений
}

\author{
() И.В. Блинков, А.О. Волхонский, Д.С. Белов, В.С. Сергевнин, \\ А.В. Черногор, Т.В. Киселева, А.В. Бондарев
}

Национальный исследовательский технологический университет „МИСиС“, Москва, Россия

E-mail: biv@misis.ru

Поступило в Редакцию 17 октября 2017 г.

Изучение макронапряженного состояния керамико-металлических покрытий $(\mathrm{Ti}, \mathrm{Al}) \mathrm{N}-\mathrm{Cu},(\mathrm{Ti}, \mathrm{Al}) \mathrm{N}-\mathrm{Ni}$ методами рентгеноструктурного анализа и по радиусу кривизны образца композита покрытие-основа (метод Стони) показало, что присутствие пластичной металлической фазы способствует значительному снижению макронапряжений в данных структурах по сравнению с макронапряжениями в керамических покрытиях (Ti,Al)N. Их абсолютные значения уменьшаются с 4.7-4.3 до $0.17-0.32 \mathrm{GPa}$. При этом покрытия $\mathrm{Ti}-\mathrm{Al}-\mathrm{Cu}-\mathrm{N}$ и $\mathrm{Ti}-\mathrm{Al}-\mathrm{Ni}-\mathrm{N}$ имеют высокие значения твердости: порядка 43 и $51 \mathrm{GPa}$ соответственно против $29 \mathrm{GPa}$ в покрытии Ti-Al-N. Полученные результаты дают основание утверждать, что определяющим фактором высокой твердости керамико-металлических покрытий является их нанозеренная структура, а не сжимающие макронапряжения.

DOI: 10.21883/PJTF.2018.04.45642.17083

Высокотвердые керамические покрытия, получаемые с использованием методов arc-PVD (вакуумно-дуговое ионно-плазменное покрытие) и магнетронного напыления, характеризуются, как правило, высоким уровнем макронапряжений, достигающим значений порядка нескольких $\mathrm{GPa}[1,2]$, что может существенно сказаться на ухудшении их адгезионной прочности с субстратом [3].

Как было показано ранее [4], введение в состав покрытий $\mathrm{Ti}-\mathrm{N}$ и $\mathrm{Ti}-\mathrm{A}-\mathrm{N}$ меди и никеля, слабо растворяющихся в них и не образующих устойчивых нитридов, способствует измельчению их зеренной структуры, переходу ее от столбчатого строения к изоморфному с 


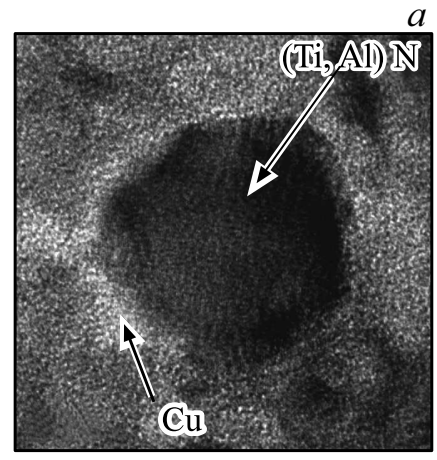

$\overline{10 \mathrm{~nm}}$

$b$

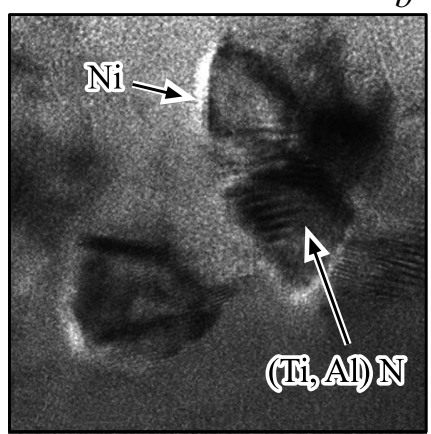

$20 \mathrm{~nm}$

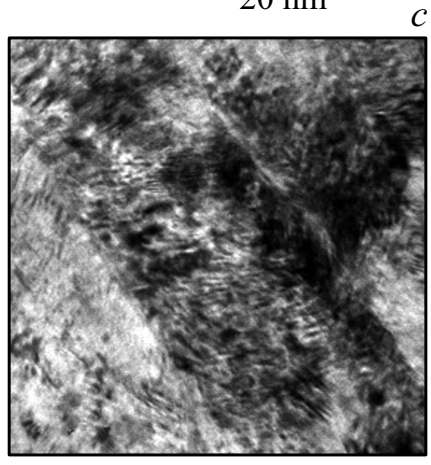

$\overline{50 \mathrm{~nm}}$

Рис. 1. Изображение структуры покрытий $\mathrm{Ti}-\mathrm{Al}-\mathrm{Cu}-\mathrm{N}(a), \mathrm{Ti}-\mathrm{Al}-\mathrm{Ni}-\mathrm{N}(b)$, $\mathrm{Ti}-\mathrm{Al}-\mathrm{N}(c)$.

соответствующим ростом значений твердости $(H)$ до $40-50 \mathrm{GPa}$ против $22-29 \mathrm{GPa}$.

Настоящая работа посвящена изучению макронапряженного состояния покрытий $(\mathrm{Ti}, \mathrm{Al}) \mathrm{N}-\mathrm{Cu},(\mathrm{Ti}, \mathrm{Al}) \mathrm{N}-\mathrm{Ni}$. Покрытия осаждались по методике, описанной в работе [4] на подложки из твердого сплава ВК6. Сформированные покрытия $\mathrm{Ti}-\mathrm{Al}-\mathrm{Cu}-\mathrm{N}$ и $\mathrm{Ti}-\mathrm{Al}-\mathrm{Ni}-\mathrm{N}$ имели однородное строение, характеризующееся равномерным распределением наноразмерных равноосных зерен нитридной фазы размером $15-20 \mathrm{~nm}$,

6 Письма в ЖТФ, 2018, том 44, вып. 4 
между которыми находились прослойки металлических фаз меди и никеля (рис. 1) [4].

Макронапряжения определялись методом $\sin ^{2} \Psi$, описанным в [5], позволяющим измерить их при постоянной глубине проникновения рентгеновских лучей в образец. При этом измеряются положения всех отражений при съемке в асимметричной геометрии. Каждое отражение имеет свой собственный угол выхода из симметричного положения $\Psi=2 \theta-\alpha$, где $\theta-$ угол дифракции, а $\alpha-$ угол между падающим лучом и образцом. По сдвигу каждой дифракционной линии рассчитывается свой период решетки $\alpha_{\Psi}(h k l)=a_{0} \sigma f(\Psi)+a_{0}$, где $a_{0}$ и $a_{\Psi}$ - параметры решетки для равновесного и напряженного состояний соответственно. Затем строится зависимость этой величины от функции

$$
f(\Psi)=\frac{1}{2} s_{2} \sin ^{2} \Psi+2 s_{1}
$$

где

$$
s_{1}=-\frac{v}{E}, \quad \frac{1}{2} s_{2}-\frac{(1+v)}{E} .
$$

Модуль Юнга $(E)$ и коэффициент Пуассона $(v)$ материала покрытия для каждой плоскости $(h k l)$ берутся свои. По тангенсу угла наклона прямой $a_{\Psi}=k f(\Psi)+b$ и периоду решетки рассчитываются напряжения $(\sigma)$.

Дифракционные исследования напряженного состояния проведены на дифрактометре Ultima 4 (Rigaku, Япония) с использованием излучения $\mathrm{Co}_{\alpha}$ при угле скольжения $\alpha=5^{\circ}$. Это значение часто используется на практике в соответствующих исследованиях [6], что дает возможность сравнить полученные результаты с данными других авторов.

Для расчета макронапряжений в пленке, толщина $\left(t_{f}\right)$ которой намного меньше толщины подложки $\left(t_{s}\right)$, по радиусу кривизны композита покрытие-основа, изогнутого за счет макронапряжений, связанных как с разным удельным объемом фаз, так и с разницей коэффициентов термического расширения покрытия и подложки, обычно используется уравнение Стони $[7,8]$

$$
\sigma=\frac{1}{6}\left(\frac{1}{R}-\frac{1}{R_{0}}\right) \frac{E_{s} t_{s}^{2}}{\left(1-v_{s}\right) t_{f}}
$$

где $E_{s}$ - модуль Юнга материала подложки [GPa], $v_{s}$ - коэффициент Пуассона материала подложки, $R$ и $R_{0}$ - радиусы кривизны композита

Письма в ЖТФ, 2018, том 44, вып. 4 

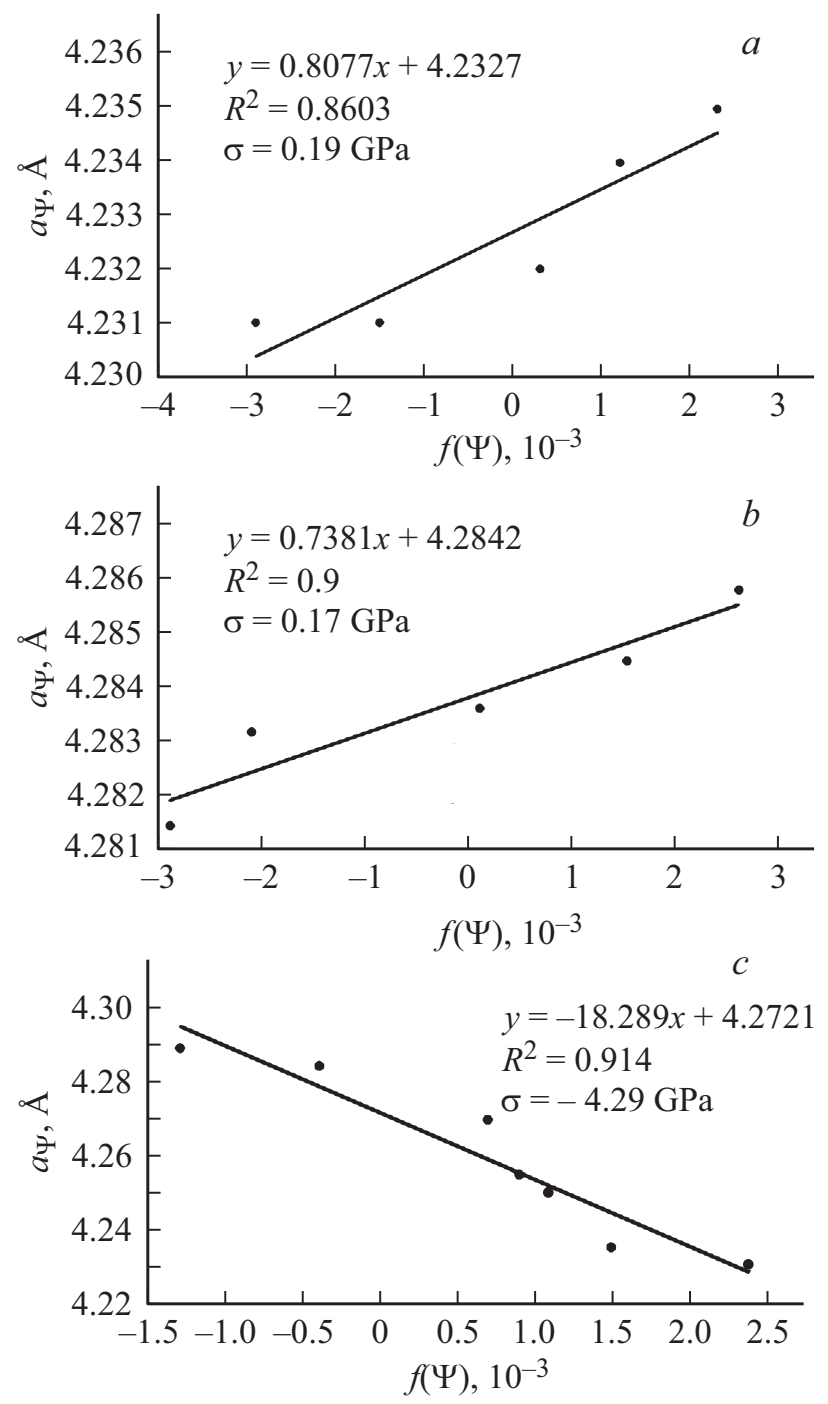

Рис. 2. Параметр решетки $a_{\Psi}$ (Ti,Al) N как функция $f(\Psi)=\frac{1}{2} s_{2} \sin ^{2} \Psi+2 s_{1}$ для покрытий $\mathrm{Ti}-\mathrm{Al}-\mathrm{Cu}-\mathrm{N}(a), \mathrm{Ti}-\mathrm{Al}-\mathrm{Ni}-\mathrm{N}(b), \mathrm{Ti}-\mathrm{Al}-\mathrm{N}(c)$, полученных на твердосплавной основе.

6* Письма в ЖТФ, 2018, том 44, вып. 4 
Состав и свойства исследуемых покрытий $\mathrm{Ti}-\mathrm{Al}-\mathrm{Cu}-\mathrm{N}$ и $\mathrm{Ti}-\mathrm{Al}-\mathrm{Ni}-\mathrm{N}$ и образца сравнения $\mathrm{Ti}-\mathrm{Al}-\mathrm{N}$

\begin{tabular}{c|c|c|c|c|c|c|c|c|c}
\hline \multirow{2}{*}{$\begin{array}{c}\text { Исследуемые об- } \\
\text { разцы покрытий }\end{array}$} & \multicolumn{3}{|c|}{ Элементный состав, at.\% } & \multirow{2}{*}{$\begin{array}{c}H, \\
\mathrm{GPa}\end{array}$} & $\begin{array}{c}E, \\
\mathrm{GPa}\end{array}$ & $\begin{array}{c}\sigma(1), \\
\mathrm{GPa}\end{array}$ & $\begin{array}{c}\sigma(2), \\
\mathrm{GPa}\end{array}$ \\
\cline { 2 - 5 } $\mathrm{Ti}-\mathrm{Al}-\mathrm{Cu}-\mathrm{N}$ & 51.2 & 2.1 & 3.1 & - & 43.6 & $43 \pm 3$ & $649 \pm 31$ & +0.19 & +0.32 \\
$\mathrm{Ti}-\mathrm{Al}-\mathrm{Ni}-\mathrm{N}$ & 48.2 & 1.9 & - & 8.0 & 41.9 & $51.5 \pm 5$ & $680 \pm 25$ & +0.17 & +0.25 \\
$\mathrm{Ti}-\mathrm{Al}-\mathrm{N}$ & 52.8 & 2.0 & - & - & 45.2 & $29.1 \pm 1$ & $561 \pm 16$ & -4.3 & -4.7
\end{tabular}

Пр имечание. $\sigma(1)$ - макронапряжения, измеренные рентгеноструктурным методом, $\sigma(2)$ - макронапряжения, измеренные по изгибу подложки с покрытием.

до и после нанесения покрытия соответственно $[\mathrm{m}]$. Они рассчитываются по профилограммам по формуле $R=\frac{L^{2}}{8 b}$, где $L-$ длина образца от края до края при изгибе $[\mathrm{m}], b$ - параметр прогиба (глубина прогиба от первоначального уровня поверхности) [m].

Профилограммы были получены с использованием оптического профилометра Veeco WYKO NT1100 (США). Толщины подложки и покрытия определялись с помощью растрового электронного микроскопа JSM-6700F.

На рис. 2 приведены характерные зависимости периода решетки нитрида ( $\mathrm{Ti}, \mathrm{Al}) \mathrm{N}$ от функции $f(\Psi)$, используемые согласно описанной выше методике для расчета макронапряжений. Составы, физикомеханические свойства исследованных покрытий и найденные значения макронапряжений представлены в таблице.

Исследование макронапряженного состояния покрытий $\mathrm{Ti}-\mathrm{Al}-\mathrm{Cu}-\mathrm{N}(a)$ и $\mathrm{Ti}-\mathrm{Al}-\mathrm{Ni}-\mathrm{N}(b)$ обоими используемыми методами в сравнении с покрытием $\mathrm{Ti}-\mathrm{Al}-\mathrm{N}$ (см. рис. 2 и таблицу) свидетельствует об уменьшении абсолютных значений макронапряжений $\mathrm{c}$ 4.7-4.3 до $0.17-0.32 \mathrm{GPa}$.

При этом, несмотря на формирование небольших по величине растягивающих макронапряжений, покрытия $\mathrm{Ti}-\mathrm{Al}-\mathrm{Cu}-\mathrm{N}$ и $\mathrm{Ti}-\mathrm{Al}-\mathrm{Ni}-\mathrm{N}$ имеют высокие значения твердости: 43 и $51 \mathrm{GPa}$ соответственно против $29 \mathrm{GPa}$ в покрытии Ti-Al-N. Релаксация как термических напряжений, возникающих из-за разницы коэффициентов линейных термических расширений, так и структурно-фазовых напряжений, появление которых определяется структурной и фазовой неоднородностью в покрытиях,

Письма в ЖТФ, 2018, том 44, вып. 4 
появляющейся в процессе их роста в керамико-металлических покрытиях, связана с сохранением меди и никеля в металлическом состоянии в составе покрытий. Ее механизм может быть обусловлен как диссипацией полей напряжения в пластичной фазе, так и разрушением в поле напряжений перемычек (стяжек вязкой фазы) в мостовой структуре $[9,10]$. Полученные результаты дают основание утверждать, что определяющим фактором высокой твердости керамикометаллических покрытий является их нанозеренная структура, а не сжимающие макронапряжения.

Исследования проведены при финансовой поддержке Российского научного фонда (проект № 17-19-01255)

\section{Список литературы}

[1] Musil J., Jaros M., Cerstvy R., Haviar S. // J. Vac. Sci. Technol. A. 2017. V. 35. P. 020601.

[2] Соболь О.В., Андреев А.А., Горбань В.Ф., Крапивка Н.А., Столбовой В.А., Сердюк И.В., Фильчиков В.Е. // Письма в ЖТФ. 2012. Т. 38. В. 13. С. 57-64.

[3] Nanostructured coatings / Eds A. Cavaleiro, J.Th. M. De Hosson. Springer Science + Business Media, LLC, 2006. $651 \mathrm{p}$.

[4] Belov D.S., Blinkov I.V., Volkhonskii A.O. // Surf. Coat. Technol. 2014. V. 260. P. 186-197.

[5] Perry A.J. // Thin Solid Films. 1990. V. 193/194. P. 463-471.

[6] Nezu A., Matsuzaka H., Yokoyama R. // Rigaku J. 2014. V. 30. N 2. P. $1276-1281$.

[7] Feng X., Huang Y., Rosakis A.J. // J. Appl. Mech. 2007. V. 74. P. 1276-1281.

[8] Добрынин А.В. // Письма в ЖТФ. 1997. Т. 23. В. 18. С. 32-36.

[9] Zhang S., Wang H.L., Ong S.-E. // Plasma Process. Polym. 2007. V. 4. P. 219-228.

[10] Wang Y.X., Zhang S. // Surf. Coat. Technol. 2014. V. 258. P. 1-16.

Письма в ЖТФ, 2018, том 44, вып. 4 